\title{
Persistent environmental endocrine-disrupting chemicals in ovarian follicular fluid and in vitro fertilization treatment outcome in women
}

\author{
Richelle D. Björvang (D) and Pauliina Damdimopoulou
}

Division of Obstetrics and Gynecology, Department of Clinical Science, Intervention and Technology, Karolinska Institutet and Karolinska University Hospital, Stockholm, Sweden

\begin{abstract}
Several international organizations have recently highlighted endocrine-disrupting chemicals (EDCs) as factors of concern in human reproduction. Since successful reproduction is dependent on timely and appropriate action of hormones, disruption of the endocrine system could lead to difficulties in conceiving or carrying a pregnancy to term. EDCs are chemicals that disrupt the endocrine system by activating or inhibiting receptors of the endocrine system, and/or altering hormone receptor expression; signal transduction; epigenetic marks; hormone synthesis, transport, distribution, and metabolism; and the fate of hormone-producing cells. Due to the increasing production of industrial chemicals over the past century and their lenient control, EDCs are now common contaminants in the environment. Consequently, everyone faces a life-long exposure to mixtures of chemicals, some of which have been identified as EDCs. As birth rates in humans are declining and the use of assisted reproductive technologies increasing, it is timely to consider possible effects of EDCs on human reproduction and fertility. In this review, we focus on persistent EDCs, their occurrence in ovarian follicular fluid, and associations to treatment outcomes in assisted reproduction. Our summary shows that despite being banned decades ago, mixtures of persistent EDCs are still detected in the ovarian follicular fluid, demonstrating direct exposure of oocytes to these chemicals. In addition, there are several reported associations between exposure and worse outcome in in vitro fertilization. Further research is therefore warranted to prove causality, which will lead towards better regulation and exposure reduction.
\end{abstract}

\section{ARTICLE HISTORY}

Received 21 November 2019

Revised 27 January 2020

Accepted 4 February 2020

\section{KEYWORDS}

Assisted reproduction; endocrine disrupting chemical; follicular fluid; persistent organic pollutant

\section{Introduction}

The phenomenon of endocrine disruption started gaining attention in the 1990s after a group of experts concluded that many compounds introduced into the environment by human activity are capable of disrupting the endocrine system of animals and humans with possibly profound consequences (1). The concept of endocrine disruption was popularized by Theo Colborn's book, Our Stolen Future, that proposed that chemical pollution is threatening the intelligence, fertility, and survival of the human race (2). Today, 25 years after the term endocrine-disrupting chemical (EDC) was coined, endocrine disruption remains a highly relevant area of research and debate in society, and the methods to identify and regulate these chemicals are still under development.

There are no international registries of numbers of chemicals in the market. The US Toxic Substance Control Act (TSCA) inventory contains over 86,000 existing chemicals. In the European Union, over 22,000 unique substances are registered under the Registration, Evaluation, Authorisation and Control (REACH) regulation. These databases only have chemicals produced or imported over $10,000 \mathrm{~kg} /$ year (TSCA) or $1000 \mathrm{~kg} /$ year $(\mathrm{REACH})$, so it is safe to assume the actual number of different chemicals that are or have been in the market is higher ${ }^{1}$. The chemical industry is one of the most profitable businesses in the world with a revenue of US\$5.7 trillion in 2019. The biggest chemical producers being China, Europe, and the United States $(4,5)$.

Unfortunately, the speed of production of new chemicals has far exceeded the speed of development of chemical health risk assessment. The side effects of uncontrolled chemical use were first discovered in 1950s when wildlife populations of birds, reptiles and mammals started drastically declining due to uncontrolled use of organochlorine pesticides like DDT (dichlorodiphenyltrichloroethane), lindane (gamma-hexachlorocyclohexane), and chlordane (octachloro4,7-methanohydroindane). In the Baltic Sea region, organochlorine chemicals nearly caused the extinction of the Baltic grey seal and the white-tailed sea eagle $(6,7)$. In the United States, populations of bald eagles and alligators declined in polluted areas $(8,9)$. These alarming occurrences among others led little by little to the establishment of international agreements for the restriction of chemicals, such as

CONTACT Pauliina Damdimopoulou pauliina.damdimopoulou@ki.se @ Division of Obstetrics and Gynecology, Department of Clinical Science, Intervention and Technology, Karolinska Institutet and Karolinska University Hospital, Stockholm, 141 86, Sweden

${ }^{1} \mathrm{~A}$ new estimate of chemicals in global commerce was published after this review was accepted, suggesting that there are 330,000 chemicals that are or have been in the market (3).

(C) 2020 The Author(s). Published by Informa UK Limited, trading as Taylor \& Francis Group.

This is an Open Access article distributed under the terms of the Creative Commons Attribution License (http://creativecommons.org/licenses/by/4.0/), which permits unrestricted use, distribution, and reproduction in any medium, provided the original work is properly cited. 
the Stockholm Convention (ratified in 2004) as well as to the development of tests for chemical risk assessment. By the time the first validated OECD guidelines for the testing of chemicals were in place in the 1980s, thousands of chemicals were already in the market.

Although organochlorine chemicals were regulated starting from the 1970s, and later internationally restricted by the Stockholm Convention, they still persist in the environment due to their extremely long half-lives. Sadly, they also still threaten the reproductive success and survival of long-lived species like killer whales (10). In addition, they are now accompanied by a plethora of newer chemicals. Current requirements for chemical safety testing in the European Union (and elsewhere) are imperfect, in particular for endocrine-disruptive activity (11). The required regulatory structure having a clear definition of EDCs, guidance documents, suitable tests, test requirements, and risk management is not in place for any sector of chemical legislation (11). In practice, this means that no regulatory risk assessment concerning endocrine-disruptive activity has been carried out for the chemicals currently in the market. According to estimates by the United Nations Environment Programme and World Health Organization (UNEP/WHO), there are at least 800 chemicals with known endocrine-disruptive activity (12). The European Union has formally recognised 13 chemicals as EDCs (11).

Several international organisations in the field of public and reproductive health have recently expressed their concerns about EDCs and human reproduction. UNEP/WHO prepared an extensive summary of EDCs in 2012 and concluded that there are many gaps in our knowledge of endocrine disruption of the female reproductive system and that test methods for screening of chemicals for endocrine disruption on female reproduction are missing (12). A few years later, the Endocrine Society released their second scientific summary on EDCs stating that several classes of chemicals ranging from pesticides to plasticisers can impair ovarian development and function, suggesting that exposure to EDCs may be associated, for example, with reduced fertility, infertility, polycystic ovarian syndrome, endometriosis, and fibroids (13). Following this, Trasande and colleagues estimated that the uncontrolled use of EDCs in Europe is associated with increased incidence of uterine fibroids and endometriosis, with an estimated annual cost of 1.4 billion euros to the taxpayers (14). In 2013, the American College of Obstetricians and Gynaecologists (ACOG) published a committee opinion on exposure to toxic environmental agents stating that 'the evidence that links exposure to toxic environmental agents and adverse reproductive and developmental health outcomes is sufficiently robust' to call for timely action to identify and reduce exposure while addressing the consequences (15). The International Federation of Gynaecology and Obstetrics (FIGO) joined this view in their 2015 opinion (16). Both ACOG and FIGO also acknowledge that while the exposure to chemicals is ubiquitous, it disproportionally affects people with low income. Hence, actions taken to prevent harm of EDC exposure in women is not only a question of gender equality, but also a matter of equality in society at large.

With this review, we wish to bring the attention of the clinicians working with reproductive-age patients to environmental chemicals as factors affecting fertility and reproductive health in women. We will first briefly outline some central concepts of endocrine disruption, and then focus on three topics: the extensive mixture exposure of all populations to industrial chemicals; the occurrence of persistent environmental chemicals with endocrine-disruptive activities in patients seeking assisted reproduction; and the potential implications of this exposure.

\section{Central concepts of endocrine disruption}

\subsection{Definitions and mechanism of action}

An EDC is defined as an 'exogenous substance or mixture that alters function(s) of the endocrine system and consequently causes adverse health effects in an intact organism, or its progeny, or (sub)populations' (17). This definition is complex as it needs both an endocrine activity and a demonstration of adverse effects as its consequence in living organisms. Adversity in the context of endocrine disruption is defined as 'a change in morphology, physiology, growth, reproduction, development or lifespan of an organism which results in impairment of functional capacity or impairment of capacity to compensate for additional stress or increased susceptibility to the harmful effects of other environmental influences' (18).

There is a wide range of mechanisms by which EDCs can interfere with the endocrine system and cause adverse effects. Classically, EDCs are thought to act via receptormediated disruption where they mimic actions of endogenous hormones such as oestrogen and androgen (agonists) or blocking interaction of the ligand with the receptor (antagonists) (19). Recently, ten key characteristics for the identification of EDCs have been proposed (19). In addition to activation or inhibition of receptors of the endocrine system, alteration of hormone receptor expression, signal transduction, epigenetic marks, hormone synthesis, transport, distribution and metabolism, and/or the fate of hormoneproducing cells are listed as mechanisms of action of EDCs (19).

In the classical mechanism of action, EDCs bind to nuclear hormone receptors, which then bind to specific response elements and influence transcription of their target genes (18). By contrast, they can also act as antagonists by binding to the receptor but not triggering the normal response (18). For example, oestrogen-disruptive activity could result from the EDC binding to the oestrogen receptor and subsequently activating (agonist) or repressing (antagonist) its downstream activity in the cell. In addition, many EDCs also bind to the aryl hydrocarbon receptor (AhR), which like the hormone receptors is a ligand-activated transcription factor. AhR is evolutionary conserved, widely expressed, and activated by a variety of xenobiotics. In response, it triggers the expression of genes involved in xenobiotic and hormone metabolism, such as CYP enzymes (e.g. CYP1A1) and UDPGT1A, by binding 
to specific response elements on DNA in the promoters of these genes (18). Moreover, AhR can also cross-talk with other nuclear receptors, implying that it can indirectly interfere with hormonal signalling pathways at large (18).

\subsection{Features of endocrine disrupting chemicals}

EDCs have diversified the field of toxicology by challenging traditional toxicological dogmas. It was originally thought that substances cause toxicity in a monotonic dose-response with consequences seen at high doses, that is, dose makes the poison. However, this is not the case with EDCs. Similar to natural hormones, EDCs can produce non-monotonic dose-response curves, where the slope of the curve changes from positive to negative or vice versa, thereby having a Uor inverted U-shape. Some of the mechanisms behind this response are receptor selectivity, receptor competition, feedback loops, and receptor number (20). This can lead to significant effects even at low doses, implying that biological effects can be observed at exposure levels typical to human exposure or lower. The endocrine system responds to very low concentrations of endogenous hormones due to high affinity of hormones to their receptors, among others. Similarly, as EDCs mimic natural hormones, they can also trigger a response at low levels (21). For example, the plastic additive bisphenol A leaching from plastic mouse cages caused disruption of meiotic spindles in mouse oocytes at exposure levels corresponding to $1 \mu \mathrm{g} /$ day per mouse (22). For comparison, the estimated human intake of bisphenol $\mathrm{A}$ varies between $10-60 \mathrm{ng} / \mathrm{kg}$ per day, suggesting exposure of $0.6-3.6 \mu \mathrm{g} /$ day for a person weighing $60 \mathrm{~kg}(23)$.

It has also been shown that there can be a long lag time from exposure until the adverse effect is seen. For example, exposure to EDCs during organogenesis is associated with increased risk of development of diseases later in life (24). Moreover, this also suggests that chemicals can cause more damage when exposure takes place during certain windows of susceptibility such as the prenatal and early postnatal period because they disrupt essential organ development $(25,26)$. An example of this is diethylstilbestrol (DES), a synthetic non-steroidal oestrogen prescribed from 1930s to 1970s to prevent miscarriages as well as decrease risk of pregnancy complications and premature delivery. As DES interfered with the reproductive tract development in utero, DES-exposed daughters had higher primary infertility, were less likely to have full-term births, and had higher likelihood of premature births, spontaneous miscarriages, and ectopic pregnancies compared with unexposed women (27-29). The DES incidence has also illustrated the multigenerational effects of EDCs as the grandchildren of DES-exposed women have increased risk of irregular menstrual cycles, amenorrhoea, ectopic pregnancy, and preterm delivery (30).

Since EDCs are ubiquitous and can be found in various consumer products, we are not exposed to a single chemical but to multiple chemicals at the same time. Common routes of exposure to EDCs are oral, respiratory, and dermal. They can also enter the body through intravenous, intramuscular, or subcutaneous routes for example during medical treatments such as IVF procedures. Developing foetuses can be exposed through placental transfer of chemicals from the mother, and neonates via breastmilk $(12,31)$. The extensive exposure to EDCs can be seen in various biomonitoring programmes in different countries where pesticides, phthalates, bisphenols, aromatic hydrocarbons, benzophenones, perfluoroalkyl substances (PFAS), chlorinated chemicals, and metals are commonly detected in the general population $(32,33)$. This mixture exposure can lead to combinatory effects of chemicals called cocktail effects. As chemicals are usually assessed individually, the hazards and risks could be underestimated because possible additive $(1+1=2)$, synergistic $(1+1>2)$, or antagonistic $(1+1<2)$ properties are not accounted for. There is continuous effort on designing and optimising statistical approaches to quantifying the effect of mixtures. Various statistical approaches have been proposed from machine learning to classical linear regression, but there is no single best approach that outperforms the others (34).

\section{Exposures and outcomes in IVF patients}

\subsection{Persistent organic pollutants}

There are various different groups of EDCs, but for the purpose of this review we focus on persistent organic pollutants (POPs). POPs are halogenated organic chemical substances that are toxic to both human and wildlife, bioaccumulative, and resistant to environmental degradation because of their stability. While most POPs are lipophilic in nature and accumulate to fatty tissues, PFAS are amphiphilic and bind to proteins. In general, POPs are also volatile at certain temperatures and may travel long distances in the atmosphere. Hence, they can be found even in areas where they were never used $(12,35)$. For humans, the largest source of POP exposure is diet. Contaminated Baltic Sea fish remains a significant source of POPs in Scandinavian countries. A list of the POPs in focus of this review, their uses, and regulations are given in Table 1 .

We choose to focus on POPs since organochlorine chemicals, which form a large part of the group, are historically the chemicals that are associated with disruption of reproductive activities in wildlife. They accumulate in humans with increasing age due to their long half-lives, and the levels therefore reflect the life-history of exposure. Currently, women postpone childbearing. The average age of first-time mothers in Sweden is 27.3 years for the whole country, and 30.3 years for its capital Stockholm (51). Delaying starting of a family means longer cumulative exposure to environmental factors, including POPs. Particularly for older women, whose oocyte quality is already declining (52), the increasing cumulative exposure to chemicals could further worsen the chances of pregnancy. In contrast to other EDCs that are easily metabolised such as phthalates, it is difficult to reduce the body burden of POPs only through lifestyle modification. For women, the body burden of lipophilic POPs is reduced when bearing a child because these chemicals cross the placenta and deposit to the foetus (53). In addition, they are also transferred to the neonate via breast milk (54). 
Table 1. Use, source, and regulation of POPs and their suggested reproductive health effects in women.

\begin{tabular}{|c|c|c|c|c|}
\hline Chemical & Use/sources & Regulation $^{\mathrm{a}}$ & $\begin{array}{l}\text { Associated health } \\
\text { effects in women }\end{array}$ & References \\
\hline PeCB and $\mathrm{HCB}$ & $\begin{array}{l}\text { Fungicide; unintentional production } \\
\text { during industrial processes }\end{array}$ & Annex $\mathrm{A}$ and $\mathrm{C}$ & $\begin{array}{l}\text { Failed implantation, increased } \\
\text { spontaneous abortion }\end{array}$ & $\begin{array}{l}\text { Mahalingaiah et al. (36); } \\
\text { Younglai et al. (37) }\end{array}$ \\
\hline HCH (lindane) & $\begin{array}{l}\text { Agricultural insecticide and } \\
\text { treatment for lice and scabies }\end{array}$ & Annex A & $\begin{array}{l}\text { Increased spontaneous abortion, } \\
\text { premature delivery, } \\
\text { endometriosis }\end{array}$ & $\begin{array}{l}\text { Upson et al. (38); US } \\
\text { Department of Health and } \\
\text { Human Services (39) }\end{array}$ \\
\hline Chlordane & $\begin{array}{l}\text { Termite treatment in food crops } \\
\text { (e.g. corn and citrus) }\end{array}$ & Annex A & Altered cycle length & Chen et al. (40) \\
\hline DDT and DDE & Disease vector control (e.g. malaria) & Annex B & $\begin{array}{l}\text { Impaired fertilization, impaired } \\
\text { lactation, infertility, reduced } \\
\text { parity, longer time-to-pregnancy, } \\
\text { uterine fibroids }\end{array}$ & $\begin{array}{l}\text { Gesink Law et al. (41); } \\
\text { Trabert et al. (42); } \\
\text { Younglai et al. (37) (43) }\end{array}$ \\
\hline PCBs & $\begin{array}{l}\text { Electrical insulation, heat transfers, } \\
\text { hydraulic systems and capacitors, } \\
\text { paints, plasticizers, dyes for } \\
\text { carbonless duplicating paper }\end{array}$ & Annex $A$ and $C$ & $\begin{array}{l}\text { Impaired response to ovulation } \\
\text { induction, impaired lactation, } \\
\text { reduced parity and fecundability, } \\
\text { longer time to pregnancy, } \\
\text { uterine fibroids }\end{array}$ & $\begin{array}{l}\text { Gennings et al. (44); Gesink } \\
\text { Law et al. (41); Trabert } \\
\text { et al. (42); Younglai } \\
\text { et al. (37) }\end{array}$ \\
\hline PBDEs & $\begin{array}{l}\text { Flame retardants added to fabrics, } \\
\text { textiles, plastics, carpets, and } \\
\text { electronical appliances }\end{array}$ & Annex A & $\begin{array}{r}\text { Failed implantation, decreased } \\
\text { fecundability, endometriosis }\end{array}$ & $\begin{array}{l}\text { Johnson et al. (45); Harley } \\
\text { et al. (46); Ploteau } \\
\text { et al. (47) }\end{array}$ \\
\hline PFASs & $\begin{array}{l}\text { Consumer products that are water-, } \\
\text { oil-, and stain-resistant (e.g. } \\
\text { Scotchgard, Teflon) }\end{array}$ & Annex B & $\begin{array}{l}\text { Longer time-to-pregnancy, } \\
\text { infertility, endometriosis }\end{array}$ & $\begin{array}{l}\text { Buck Louis et al. (48); } \\
\text { Campbell et al. (49); Fei } \\
\text { et al. (50) }\end{array}$ \\
\hline
\end{tabular}

${ }^{\mathrm{a}}$ Regulation under the Stockholm Convention: Annex A, elimination of production and use; Annex B, restrict production and use; Annex C, reduce unintentional releases.

DDE: dichlorodiphenyldichloroethylene; DDT: dichlorodiphenyltrichloroethane; HCB:hexachlorobenzene; HCH: hexachlorocyclohexane; PBDE: polybrominated diphenyl ether; PCB: polychlorinated biphenyl; PeCB: pentachlorobenzene; PFAS: perfluoroalkyl substance.

\subsection{POPs in follicular fluid and associations to outcomes}

With the advent of assisted reproductive technologies, follicular fluid has become accessible for evaluating the direct exposure of oocytes to EDCs. Several studies have measured concentrations of POPs in follicular fluid, and some also analysed the associations to treatment outcomes. We summarise the literature on POPs in follicular fluid in Table 2. The lipophilic POPs have been adjusted for sample lipid content in some studies. Although the exposure levels were reported in different units (e.g. $\mathrm{ng} / \mathrm{mL}$ or $\mathrm{ng} / \mathrm{g}$ wet weight or $\mathrm{ng} / \mathrm{g}$ lipids), which made direct comparisons between studies challenging, the summary shows direct exposure of oocytes to mixtures of POPs, which could lead to cocktail effects. Only three studies $(57,61,65)$ gave account of this mixture exposure with the use of principal component analysis.

As these cohorts were composed of women undergoing IVF treatment, information on ovarian reserve, endometrial thickness, oocyte quality, fertilization rate, embryo quality, and live birth were readily available to further investigate the impact of POPs on human reproduction, specifically on IVF endpoints. Approximately half of the studies analysed association between exposure and outcome. Common outcomes evaluated were oocyte quality, implantation rate, and live birth as well as endometrial thickness. While some studies did not find any association between chemicals and IVF outcomes, others found that in particular the lipophilic POPs were associated with lower fertilisation rates and poorer embryo quality after adjusting for covariates such as age, body mass index, and oestradiol. For example, dichlorodiphenyldichloroethylene (DDE), a metabolite of DDT, was found to be associated with lower oocyte quality in three studies $(43,57,60)$, while two failed to find associations $(56,59)$. The indicator PCBs (PCBs 28, 52, 101, 138, 153, and 180) were associated with lower oestradiol, thinner endometrium, and lower fertilization rates in most studies $(57,60,62)$. The PFAS compounds were evaluated in two studies and found to be associated with higher androgen levels and higher embryo quality $(65,66)$. It is clear that more studies are warranted, both experimental and epidemiological, to interpret these associations. It should also be noted that the reported cohort studies are relatively small, most having fewer than 100 participants, which clearly limits the statistical power.

\subsection{A way forward}

Studying the effects of POPs on fertility in women is challenging, as fertility and fecundability depend on multiple factors. In addition, women (and couples) are exposed to multiple POPs, which makes statistical analyses challenging. Ideally, similar chemicals are grouped together, allowing comparison of toxic equivalency values which is currently done for dioxin and dioxin-like compounds. Alternatively, statistical methods that can handle highly correlated exposures and non-linear relationships that are typical for these chemicals should be further developed. Effects seen only in some quantiles of exposure should not be disregarded but rather explored further. Lastly, human folliculogenesis lasts for months, and during this time cytoplasmic and nuclear maturation take place including epigenetic changes and germline imprinting. Exposure assessment during preconception could help identify chemicals with adverse effects on oocyte quality.

Population studies give a good starting point for gauging associations between exposures and reproductive outcomes. However, for proving causality, experimental models will be needed. Better understanding of mechanisms underlying 


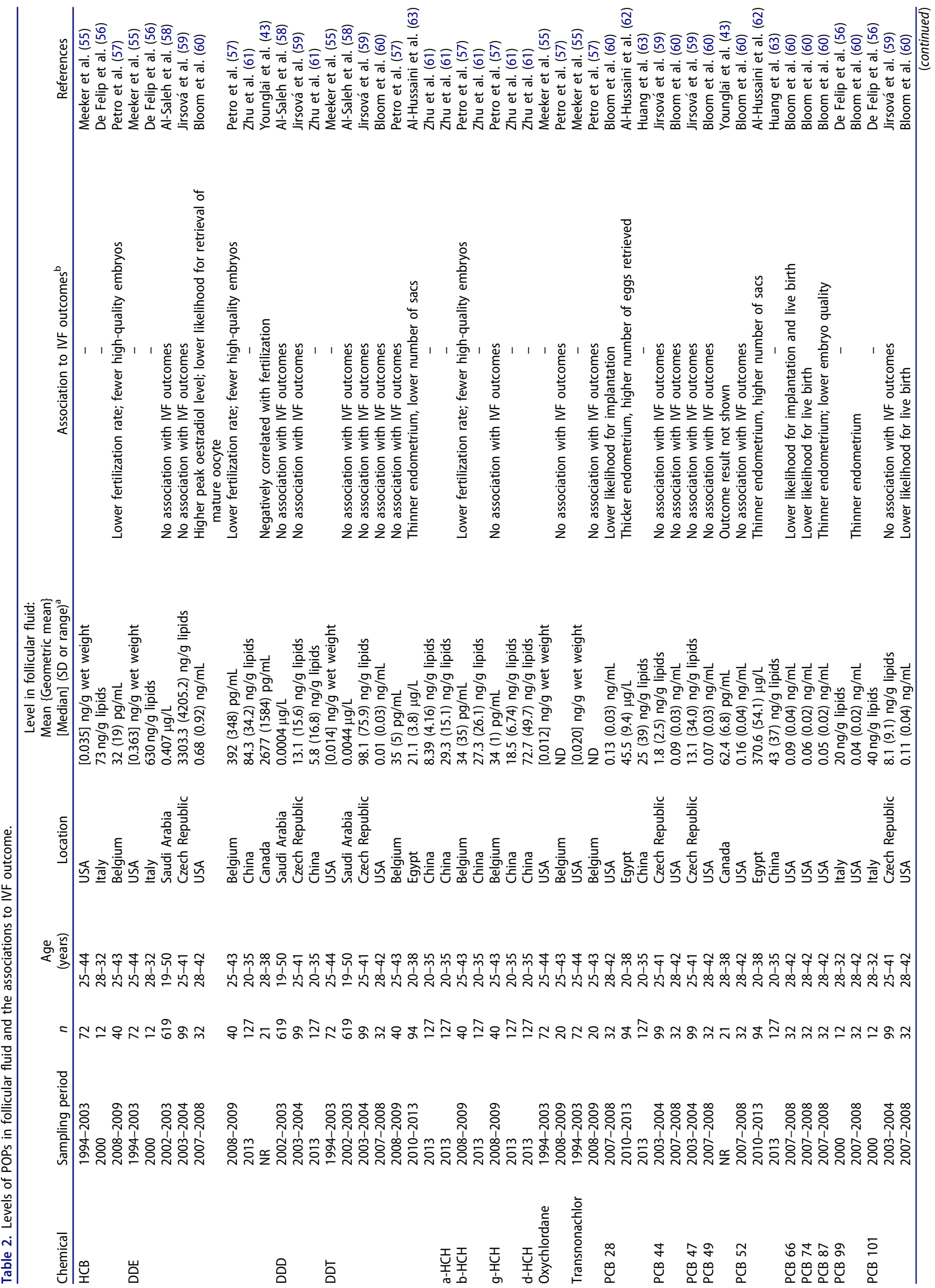









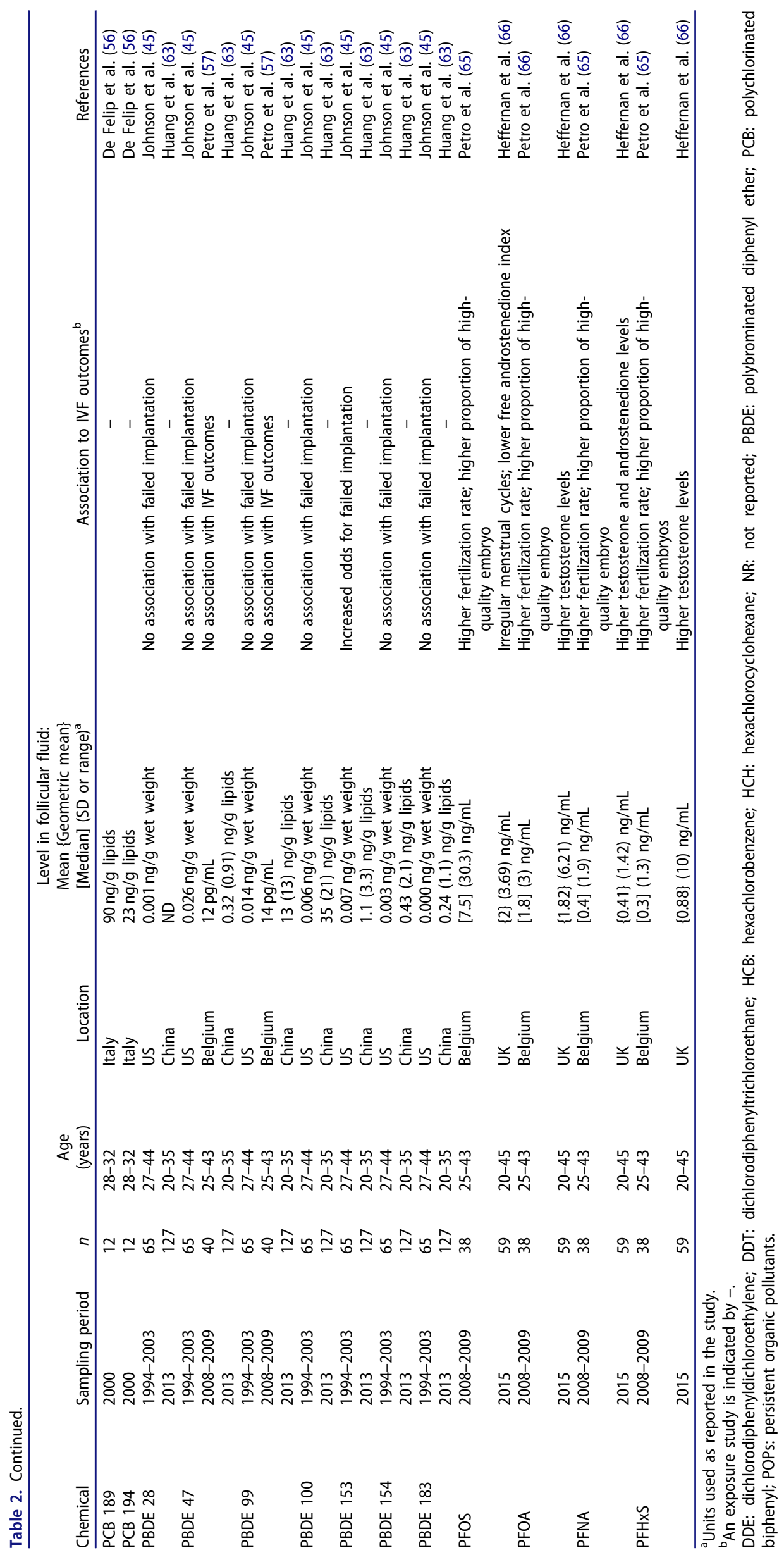


folliculogenesis, oocyte quality, ovarian aging, and endometrial receptivity will be needed in order to tailor better assays for chemical safety testing.

\section{Conclusions}

Multiple studies have identified cocktails of POPs in ovarian follicular fluid of reproductive-aged women across the world, although the use of most of the chemicals in focus in this review was restricted decades ago (Tables 1 and 2). Specifically, lipophilic organochlorine chemicals such as DDE and PCBs were associated with worse outcomes in IVF treatments (Table 2). In addition, these compounds have also been linked to other adverse reproductive outcomes in women (Table 1). Originally, organochlorine chemicals were found to be toxic for reproduction in wildlife animal populations. Our review suggests that they may also worsen the chances of successful fertility treatments in humans. Although cohort studies give information about significant associations between exposures and outcomes, they cannot demonstrate causality or inform about associated mechanisms. Therefore, experimental models will be needed for proving endocrine mechanisms of action as well as causality.

Because EDCs affect not only reproductive function of women but also the health of the offspring, it is of utmost importance that all action should be taken to reduce exposure. Advising women and families on the use of consumer products, healthy diets, and home supplies represents a good start and raises awareness. However, populations can only truly be protected with better chemical regulations that prevent harmful chemicals from entering the market. Therefore, research proving causal effects between EDC exposures and adverse effects in humans is urgently needed.

\section{Disclosure statement}

No potential conflict of interest was reported by the author(s)

\section{Funding}

This work was supported by Jane and Aatos Erkko Foundation, Swedish Research Council FORMAS, and European Union's Horizon 2020 research and innovation programme under grant agreement [No 825100; FREIA].

\section{Notes on contributors}

Richelle D. Björvang, $\mathrm{MD}$, is a $\mathrm{PhD}$ student at Karolinska Institutet, Stockholm, Sweden.

Pauliina Damdimopoulou, $\mathrm{PhD}$, is an associate professor and a senior researcher at Karolinska Institutet. Her research group focuses on chemicals and fertility in women.

\section{ORCID}

Richelle D. Björvang (ID http://orcid.org/0000-0002-3619-2257 Pauliina Damdimopoulou (D) http://orcid.org/0000-0001-8458-0855

\section{References}

1. Colborn T, Clement C. Chemically-induced alterations in sexual and functional development: the wildlife/human connection. In: Advances in Modern Environmental Toxicology. Princeton, NJ: Princeton Scientific Publishing Co.; 1992.

2. Colborn T, Dumanoski D, Peterson Myers J. Our stolen future. New York: Dutton; 1996.

3. Wang Z, Walker GW, Muir DCG, Nagatani-Yoshida K. Toward a global understanding of chemical pollution: $A$ first comprehensive analysis of national and regional chemical inventories. Environ Sci Technol. 2020. DOI: 10.1021/acs.est.9b06379

4. Cefic. Facts and figures of the European chemical industry [Internet]. 2018. [cited 2019 Nov 21]. Available at: https://cefic.org.

5. Oxford Economics. The Global chemical industry: catalyzing growth and addressing our world's sustainability challenges. Washington, DC: ICCA; 2019.

6. Jenssen BM. An overview of exposure to, and effects of, petroleum oil and organochlorine pollution in grey seals (Halichoerus grypus). Sci Total Environ. 1996;186:109-18.

7. Helander B, Olsson A, Bignert A, Asplund L, Litzén K. The role of $\mathrm{DDE}, \mathrm{PCB}$, coplanar $\mathrm{PCB}$ and eggshell parameters for reproduction in the white-tailed sea eagle (Haliaeetus albicilla) in Sweden. Ambio. 2002;3:386-403.

8. Colborn T. Epidemiology of great lakes bald eagles. J Toxicol Environ Heal. 1991;33:395-453.

9. Guillette LJ Jr, Gross TS, Masson GR, Matter JM, Percival FH, Woodward AR. Developmental abnormalities of the gonad and abnormal sex hormone concentrations in juvenile alligators from contaminated and control lakes in Florida. Environ Health Perspect. 1994;102:680-8.

10. Desforges JP, Hall A, Mcconnell B, Rosing-Asvid A, Barber JL, Brownlow $A$, et al. Predicting global killer whale population collapse from PCB pollution. Science. 2018;361:1373-6.

11. Demeneix B, Slama R. Endocrine disruptors: from scientific evidence to human health protection. Brussels: Policy Department for Citizens' Rights and Constitutional Affairs; 2019.

12. Bergman Å, Heindel J, Jobling S, Kidd K, Zoeller RT. State of the science of endocrine disrupting chemicals. United Nations Environment Programme and the World Health Organization; 2013.

13. Gore AC, Chappell VA, Fenton SE, Flaws JA, Nadal A, Prins GS, et al. EDC-2: The Endocrine Society's second scientific statement on endocrine-disrupting chemicals. Endocr Rev. 2015;36:E1-150.

14. Hunt PA, Sathyanarayana S, Fowler PA, Trasande L. Female reproductive disorders, diseases, and costs of exposure to endocrine disrupting chemicals in the European Union. J Clin Endocrinol Metab. 2016;101:1562-70.

15. American College of Obstetricians and Gynecologists Committee on Health Care for Underserved Women; American Society for Reproductive Medicine Practice Committee; University of California SFP on RH and the E. Exposure to Toxic Environmental Agents [Internet]. 2013 [cited 2019 Nov 20]. Available at: http:// prhe.ucsf.

16. Di Renzo GC, Conry JA, Blake J, Defrancesco MS, Denicola N Martin $\mathrm{JN}$, et al. International Federation of Gynecology and Obstetrics (FIGO) opinion on reproductive health impacts of exposure to toxic environmental chemicals. Int J Gynecol Obstet. 2015;131:219-25.

17. Kortenkamp A, Martin O, Faust M, Evans R, Mckinlay R, Orton F, et al. State of the art assessment of endocrine disrupters [Internet]. 2011 [cited 2019 Aug 8]. Available at: https://ec.europa. eu/environment/chemicals/endocrine/pdf/sota_edc_final_report. pdf.

18. Rüegg J, Penttinen-Damdimopoulou $P$, Mäkelä S, Pongratz I, Gustafsson JÅ, Receptors mediating toxicity and their involvement in endocrine disruption. In: Luch A, editor. Molecular, clinical and environmental toxicology. Volume 1: Molecular toxicology. Switzerland: Birkhäuser Verlag; 2009. p. 289-323. 
19. La Merrill MA, Vandenberg LN, Smith MT, Goodson W, Browne P, Patisaul HB, et al. Consensus on the key characteristics of endocrine-disrupting chemicals as a basis for hazard identification. Nat Rev Endocrinol. 2020;16:45-57.

20. Vandenberg LN. Non-monotonic dose responses in studies of endocrine disrupting chemicals: bisphenol $\mathrm{A}$ as a case study. Dose Response. 2014;12:259-76.

21. Vandenberg LN, Colborn T, Hayes TB, Heindel JJ, Jacobs DR, Lee $\mathrm{D}-\mathrm{H}$, et al. Hormones and endocrine-disrupting chemicals: lowdose effects and nonmonotonic dose responses. Endocr Rev. 2012;33:378-455.

22. Hunt PA, Koehler KE, Susiarjo M, Hodges CA, llagan A, Voigt RC, et al. Bisphenol A exposure causes meiotic aneuploidy in the female mouse. Curr Biol. 2003;13:546-53.

23. Huang RP, Liu ZH, Yuan SF, Yin H, Dang Z, Wu PX. Worldwide human daily intakes of bisphenol A (BPA) estimated from global urinary concentration data (2000-2016) and its risk analysis. Environ Pollut. 2017;230:143-52.

24. Birnbaum LS, Miller MF. Prenatal programming and toxicity (PPTOX) introduction. Endocrinology 2015;156:3405-7.

25. Schug TT, Janesick A, Blumberg B, Heindel JJ. Endocrine disrupting chemicals and disease susceptibility. J Steroid Biochem Mol Biol. 2011;127:204-15.

26. Barouki R. Endocrine disruptors: revisiting concepts and dogma in toxicology. C R Biol. 2017;340:410-3.

27. Kaufman RH, Adam E, Hatch EE, Noller K, Herbst AL, Palmer JR, et al. Continued follow-up of pregnancy outcomes in diethylstilbestrol-exposed offspring. Obstet Gynecol. 2000;96:483-9.

28. Reed $C E$, Fenton SE. Exposure to diethylstilbestrol during sensitive life stages: a legacy of heritable health effects. Birth Defect Res C. 2013;99:134-46.

29. Milhan D. DES exposure: implications for childbearing. Int J Childbirth Educ. 1992;7:21-8.

30. Titus L, Hatch EE, Drake KM, Parker SE, Hyer M, Palmer JR, et al. Reproductive and hormone-related outcomes in women whose mothers were exposed in utero to diethylstilbestrol (DES): A report from the US National Cancer Institute DES Third Generation Study. Reprod Toxicol. 2019;84:32-8.

31. Mamsen LS, Björvang RD, Mucs D, Vinnars M-T, Papadogiannakis $\mathrm{N}$, Lindh $\mathrm{CH}$, et al. Concentrations of perfluoroalkyl substances (PFASs) in human embryonic and fetal organs from first, second, and third trimester pregnancies. Environ Int. 2019;124:482-92.

32. Porta $M$, Puigdomènech $E$, Ballester $F$, Selva J, Ribas-Fitó $N$, Llop $S$, et al. Monitoring concentrations of persistent organic pollutants in the general population: the international experience. Environ Int. 2008;34:546-61.

33. Crinnion WJ. The CDC fourth national report on human exposure to environmental chemicals: what it tells us about our toxic burden and how it assists environmental medicine physicians. Altern Med Rev 2010;15:101-8.

34. Taylor KW, Joubert BR, Braun JM, Dilworth C, Gennings C, Hauser $\mathrm{R}$, et al. Statistical approaches for assessing health effects of environmental chemical mixtures in epidemiology: lessons from an innovative workshop. Env Heal Perspect 2016;124:A227-9.

35. Stockholm Convention. Listing of POPs in the Stockholm Convention [Internet]. 2008 [cited 2019 Aug 15]. Available at: http://www.pops.int/TheConvention/ThePOPs/AllPOPs/tabid/2509/ Default.aspx.

36. Mahalingaiah S, Missmer SA, Maity A, Williams PL, Meeker JD, Berry $\mathrm{K}$, et al. Association of hexachlorobenzene (HCB), dichlorodiphenyltrichloroethane (DDT), and dichlorodiphenyldichloroethylene (DDE) with in vitro fertilization (IVF) outcomes. Environ Health Perspect. 2012;120:316-20.

37. Younglai EV, Holloway AC, Foster WG. Environmental and occupational factors affecting fertility and IVF success. Hum Reprod Update. 2005;11:43-57.

38. Upson K, De Roos AJ, Thompson ML, Sathyanarayana S, Scholes D, Boyd Barr D, et al. Organochlorine pesticides and risk of endometriosis: findings from a population-based case-control study. Environ Health Perspect. 2013;121:1319-24.
39. US Department of Health and Human Services. Toxicological profile for alpha-, beta-, gamma-, and delta-hexachlorocyclohexane [Internet]. 2005 [cited 2019 Aug 16]. Available at: https://www. atsdr.cdc.gov/toxprofiles/tp43.pdf.

40. Chen MW, Santos HM, Que DE, Gou YY, Tayo LL, Hsu YC, et al. Association between organochlorine pesticide levels in breast milk and their effects on female reproduction in a Taiwanese population. Int J Environ Res Public Health. 2018;15:931.

41. Gesink Law DC, Klebanoff MA, Brock JW, Dunson DB, Longnecker MP. Maternal serum levels of polychlorinated biphenyls and 1,1dichloro-2,2- bis(p-chlorophenyl)ethylene (DDE) and time to pregnancy. Am J Epidemiol. 2005;162:523-32.

42. Trabert B, Chen $Z$, Kannan $K$, Matthew Peterson $C$, Pollack AZ, Sun $\mathrm{L}$, et al. Persistent organic pollutants (POPs) and fibroids: results from the ENDO study. J Expo Sci Environ Epidemiol. 2015;25: 278-85.

43. Younglai EV, Foster WG, Hughes EG, Trim K, Jarrell JF. Levels of environmental contaminants in human follicular fluid, serum, and seminal plasma of couples undergoing in vitro fertilization. Arch Environ Contam Toxicol. 2002;43:121-6.

44. Gennings C, Carrico C, Factor-Litvak P, Krigbaum N, Cirillo PM, Cohn BA. A cohort study evaluation of maternal PCB exposure related to time to pregnancy in daughters. Environ Health. 2013; 12:66.

45. Johnson PI, Altshul L, Cramer DW, Missmer SA, Hauser R, Meeker JD. Serum and follicular fluid concentrations of polybrominated diphenyl ethers and in-vitro fertilization outcome. Environ Int. 2012;45:9-14.

46. Harley KG, Marks AR, Chevrier J, Bradman A, Sjödin A, Eskenazi B. PBDE concentrations in women's serum and fecundability. Environ Health Perspect. 2010;118:699-704.

47. Ploteau S, Cano-Sancho G, Volteau C, Legrand A, Vénisseau A, Vacher $V$, et al. Associations between internal exposure levels of persistent organic pollutants in adipose tissue and deep infiltrating endometriosis with or without concurrent ovarian endometrioma. Environ Int. 2017;108:195-203.

48. Buck Louis GM, Sundaram R, Schisterman EF, Sweeney AM, Lynch $\mathrm{CD}$, Gore-Langton RE, et al. Persistent environmental pollutants and couple fecundity: the LIFE study. Environ Health Perspect. 2013;121:231-6.

49. Campbell S, Raza M, Pollack AZ. Perfluoroalkyl substances and endometriosis in US women in NHANES 2003-2006. Reprod Toxicol. 2016; 65:230-5.

50. Fei C, Mclaughlin JK, Lipworth L, Olsen J. Maternal levels of perfluorinated chemicals and subfecundity. Hum Reprod. 2009;24: 1200-5.

51. National Board of Health and Welfare. Statistics and data [Internet]. 2019 [cited 2019 Nov 20]. Available at: https://www. socialstyrelsen.se/statistik-och-data/statistik/.

52. Silber SJ, Kato K, Aoyama N, Yabuuchi A, Skaletsky H, Fan Y, et al. Intrinsic fertility of human oocytes. Fertil Steril. 2017;107:1232-7.

53. Curley A, Copeland F, Kimbrough R. Chlorinated hydrocarbon insecticides in organs of stillborn and blood of newborn babes. Arch Env Heal. 1969;19:628-32.

54. Müller M, Polder A, Brynildsrud OB, Grønnestad R, Karimi M, Lie E, et al. Prenatal exposure to persistent organic pollutants in Northern Tanzania and their distribution between breast milk, maternal blood, placenta and cord blood. Environ Res. 2019;170: 433-42.

55. Meeker JD, Missmer SA, Altshul L, Vitonis AF, Ryan L, Cramer DW, et al. Serum and follicular fluid organochlorine concentrations among women undergoing assisted reproduction technologies. Environ Health. 2009;8:32.

56. De Felip E, Di Domenico A, Miniero R, Silvestroni L. Polychlorobiphenyls and other organochlorine compounds in human follicular fluid. Chemosphere. 2004;54:1445-9.

57. Petro EML, Leroy J, Covaci A, Fransen E, De Neubourg D, Dirtu AC, et al. Endocrine-disrupting chemicals in human follicular fluid impair in vitro oocyte developmental competence. Hum Reprod. 2012;27:1025-33. 
58. Al-Saleh I, Coskun S, El-Doush I, Billedo G, Mashhour A, Jaroudi K, et al. Outcome of in-vitro fertilization treatment and DDT levels in serum and follicular fluid. Med Sci Monit 2009;15:320-33.

59. Jirsová S, Mašata J, Jech L, Zvárová J. Effect of polychlorinated biphenyls (PCBs) and 1,1,1-trichloro-2,2,-bis (4-chlorophenyl)-ethane (DDT) in follicular fluid on the results of in vitro fertilizationembryo transfer (IVF-ET) programs. Fertil Steril. 2010;93:1831-6.

60. Bloom MS, Fujimoto VY, Storm R, Zhang L, Butts CD, Sollohub D, et al. Persistent organic pollutants (POPs) in human follicular fluid and in vitro fertilization outcomes, a pilot study. Reprod Toxicol. 2017;67:165-73.

61. Zhu Y, Huang B, Li QX, Wang J. Organochlorine pesticides in follicular fluid of women undergoing assisted reproductive technologies from central China. Environ Pollut. 2015;207:266-72.

62. Al-Hussaini TK, Abdelaleem AA, Elnashar I, Shabaan OM, Mostafa $\mathrm{R}$, El-Baz $M A H$, et al. The effect of follicullar fluid pesticides and polychlorinated biphenyls concentrations on intracytoplasmic sperm injection (ICSI) embryological and clinical outcome. Eur J Obstet Gynecol Reprod Biol. 2018;220:39-43.

63. Huang $Y$, Yan M, Nie H, Wang W, Wang J. Persistent halogenated organic pollutants in follicular fluid of women undergoing in vitro fertilization from China: Occurrence, congener profiles, and possible sources. Environ Pollut. 2019;244:1-8.

64. Pauwels A, Covaci A, Delbek L, Punjabi U, Schepens PJ. The relation between levels of selected PCB congeners in human serum and follicular fluid. Chemosphere. 1999;39:2433-41.

65. Petro EML, D'Hollander W, Covaci A, Bervoets L, Fransen E, De Neubourg D, et al. Perfluoroalkyl acid contamination of follicular fluid and its consequence for in vitro oocyte developmental competence. Sci Total Environ. 2014;496:282-8.

66. Heffernan AL, Cunningham TK, Drage DS, Aylward LL, Thompson $\mathrm{K}$, Vijayasarathy $\mathrm{S}$, et al. Perfluorinated alkyl acids in the serum and follicular fluid of UK women with and without polycystic ovarian syndrome undergoing fertility treatment and associations with hormonal and metabolic parameters. Int J Hyg Environ Health. 2018;221:1068-75. 